https://doi.org/10.26480/esp.02.2017.17.18

\title{
FEASIBILITY STUDY OF LOW DENSITY WASTE PLASTIC IN NON-LOAD BEARING ASPHALT PAVEMENT IN DISTRICT FAISALABAD
}

\section{Syed Shahzaib Ali ${ }^{1}$, Nimrah Ijaz ${ }^{1}$, Nafeesa Aman ${ }^{1}$, Mohsin Noor ${ }^{1}$ \\ ${ }^{1}$ Department of Structures and Environmental Engineering, Faculty of Agricultural Engineering \& Technology, University of Agriculture, Faisalabad, Pakistan.}

This is an open access article distributed under the Creative Commons Attribution License, which permits unrestricted use, distribution, and reproduction in any medium, provided the original work is properly cited

\section{ARTICLE DETAILS}

\section{Article history:}

Received 25 August 2017

Accepted 20 October 2017

Available online 7 November 2017

Keywords:

waste plastic, aggregate, bitumen and plastic modified aggregate

\begin{abstract}
The rapid growth of population and development of industrial field is contributing to massive waste pollution in which plastic waste is considered as most difficult waste to deal with due to its non-biodegradable nature. This lead to various impact on environment as well as all living things. Many of the waste produced due to human activity will remain in the environment for long period of time leading to various environmental problem. To overcome this problem a study is conducted in which plastic waste is effectively utilized with bitumen a binding material in construction of flexible pavements to enhance its stability and water resistant capacity. Cleaned plastic waste is shredded to a size of $2.76 \mathrm{~mm}-4 \mathrm{~mm}$ is mixed with hot bitumen mix and then this waste plastic added bitumen is mixed with hot aggregate and the end product is used as laying material for road construction. The objective of this study is to give an innovative idea for effective use of plastic waste and recommend a favorable percentage of plastic for replacement of bitumen. This paper also includes some tests performed on aggregate and bitumen.
\end{abstract}

\section{INTRODUCTION}

Nowadays plastic is considered as a part of life. It is used at every step of life from manufacturing to disposal processes. Due to industrial advancement there is increase in production and plastic is considered as a cheaper raw material. Plastic is basically a polymer having ability of changing shape and non-biodegradable in nature. There are two types of plastic; thermoses and thermoplastics. Thermoses are those plastics which turn into solid form when exposed to high temperature. They are used because of their toughness and strength in construction and automobiles works. On the other hand thermoplastics liquefy upon heating and maintain their original shapes on room temperature. Due to this property they are used for jugs, bottles etc. Rapid growth of population and industries is resulting into increase in waste production at global level which leads to a serious problem of handling this waste in an efficient way. Plastic waste disposal is pointed out as most difficult task as according to a study it is said that plastic can remain stable for about 4500 years on earth without any degradation. So this increases amount of waste day by day. In Faisalabad current collection rate of Faisalabad waste management company (FWMC) is about 60\%-65 or (FWMC) provided services to 4 towns having approximate 34 zones overall and 113 union councils (UC.s). In overall Faisalabad daily production of waste is 1650 tons per day which includes $6.60 \%$ of plastic. (FWMC).

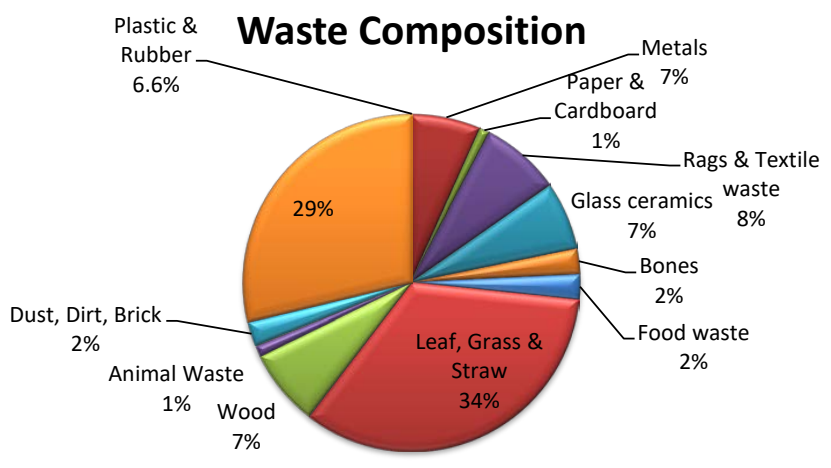

Figure 1: Percentage of different waste types in Faisalabad

So this study shows the use of this plastic in road construction to utilize this waste to control environmental problems in Faisalabad. So we use low density plastic waste like wrappers, bottles, bags etc. as a coating layer on aggregate mix and used as a replacement of bitumen. Use of plastic mix decreases the requirement of bitumen by $10 \%$, by enhancing its durability and firmness in an eco-friendly way [1]. Substitution of $10-15 \%$ bitumen by plastic retain Rs 35000 - Rs 45000 per Km of road stretch. Addition of plastic in road construction eradicates the shrinkage and cracking of road surface level [2]. Use of plastic not only gives strength to infrastructure but also decrease the penetration ability of material as well as ductility. By using favorable percentage of plastic between ranges of $5 \%$ to $10 \%$ can lead to reduction in total material cost by $7.99 \%$ and minimize the effect of bleeding in hot climatic regions. She also said that this replacement not only solve the problem of soil and water pollution, but also minimize the noise pollution due to sound absorption ability of plastic [3]. Up to $10 \%$ of plastic addition can be considered as optimum range based on Marshal Stability test. This addition increases the properties of bitumen and aggregate as well as an eco-friendly technique to deal with plastic waste disposal issue and gives more flexibility to infrastructure [4]. Up to $12 \%$ of bitumen can be replaced by plastic which as a result use plastic waste in a very productive way and intensify the binder performance and decreases the moisture absorbance capacity of road [5]. Addition of plastic in road construction process increases the melting point of bitumen, extend life of road and build up more sound resistant ability in roads. Also binding properties increases and is a good way to get rid of the plastic waste disposal problem [6]. Plastic waste causes lots of environmental issues. Waste plastic causes water stagnation, choking of drains, many diseases and also resist against soil to penetrate water to fulfil the plant requirement [7]. So to deal with these problems, an effective, environment friendly and economical method was needed. So the basic purpose of this study is to compare properties of plain bitumen mix with plastic mix bitumen to check the durability and stability of the road in hot climatic region like Faisalabad having temperature up to 50oc [8]. Another objective is to give an idea to overcome the issue of plastic waste disposal in a productive and cost-efficient way to reduce the pollution problems which we are facing due to this plastic material.

\section{METHODOLOGY}

Methodology was consisting on two phases first phase was data collection and second phase was analysis. General investigation of plastic waste materials and aggregate and bitumen requires various field tests. This part was divided into three sections first section represent physical requirements of aggregate and bitumen, second represent the properties of plastic, third shows the preparation of plastic waste material for shredding. In site detail the whole process were done in Faculty of Agriculture Engineering and Technology at University of Agriculture Faisalabad. Plastic waste were collected like bags, wrappers of biscuits and chocolates, bottles made of PE (polyethylene) and PP (polypropylene) and collected plastic waste were de-dusting or washing if required. The collected waste plastic was cut into size between $2.36 \mathrm{~mm}-4.76 \mathrm{~m}$ by using shredding machine. Care was taken that PVC waste should be separated out before further processing. After this step next was the aggregate mix is heated up to 1650 $\mathrm{C}$ and it transfer to mixing chamber. Also bitumen were heated at $160 \mathrm{o} \mathrm{C}$. Plastic waste were added slowly in bitumen after heated at $160 \mathrm{oC}$ mixture was stirred manually around $20 \mathrm{~min}$. but for all this monitoring of exact 
temperature is very important during this process and temperature must retain about $160 \mathrm{oC}-1650 \mathrm{C}$. At the mixing chamber the plastic waste containing bitumen were added over the hot aggregate and mixed uniformly [9]. Then this final result is used for laying roads. The road laying temperature is $110 \mathrm{oC}-120 \mathrm{oC}$

\section{RESULTS AND DISCUSSION}

The study shows that by the replacement of $10 \%$ by weight waste plastic increase its stability. Marshall stability and flow values along with density; air voids in the total mix, voids in the mineral aggregate, or voids filled with asphalt, or both, filled with asphalt are used for laboratory mix design and evaluation of asphalt mixtures. In addition, Marshall Stability and flow can be used to monitor the plant process of producing asphalt mixture. Marshall Stability and flow may also be used to relatively evaluate different mixes and the effects of conditioning such as with water.

Table1: Summary of Marshal Stability Test

\begin{tabular}{|l|l|l|}
\hline \multirow{2}{*}{ Bitumen Content } & \multicolumn{2}{|c|}{ Stability (KN) } \\
\cline { 2 - 3 } & Plain bitumen & $\mathbf{1 0} \%$ bitumen replaced by plastic waste \\
\hline 4.5 Percent & 17.03 & 20.28 \\
\hline 5.0 Percent & 17.18 & 22.43 \\
\hline 5.5 Percent & 17.68 & 22.43 \\
\hline 6.0 Percent & 17.61 & 21.18 \\
\hline
\end{tabular}

Table 2: Summary of Flow mm Test

\begin{tabular}{|l|l|l|}
\hline \multirow{2}{*}{} & \multicolumn{2}{|c|}{} \\
\cline { 2 - 3 } & Plain bitumen & $\mathbf{1 0} \%$ bitumen replaced by plastic waste \\
\hline 4.5 Percent & 4.08 & 4.57 \\
\hline 5.0 Percent & 4.23 & 4.82 \\
\hline 5.5 Percent & 4.40 & 5.05 \\
\hline 6.0 Percent & 5.10 & 5.15 \\
\hline
\end{tabular}

Typically, Marshall Stability is the peak resistance load obtained during a constant rate of deformation loading sequence. However, depending on the composition and behavior of the mixture, a less defined type of failure has been observed. As an alternative method, Marshall Stability can also be defined as the load obtained, when the rate of loading increase begins to decrease. The magnitude of Marshall Stability varies with aggregate type and grading and bitumen type, grade and amount. The Marshall Stability test conducted during the study with different percentages of plastic waste and size of sample showed the values of Stability also increasing for fixed rate of $10 \%$ of plastic waste.

\section{CONCLUSION}

This research concluded that waste plastic added asphalt can be used for better performance of road. Waste plastic added asphalt have binder performance and it also reduce the voids. Waste plastic added asphalt is better than plain asphalt. When use for road construction prepare with high temperature suitable for tropical region. Using waste plastic added asphalt decrease penetration increase roads loading capacity and more resist again water. It decreased pot-hole in roads structure. Using waste plastic in asphalt the asphalt quantity reduced in $\%$ by using waste plastic. Plastic added asphalt increase stability of structure. Research concluded that by the replacement of waste plastic $10 \%$ by weight is good for road construction it can reduce the cost almost by $8 \%$ of whole and it increase its life also and increase its efficiency reduced its pothole structure.

\section{RECOMMENDATION}

1. Asphalt properties modified by the addition of waste plastic.

2. $10 \%$ to $12 \%$ range of waste plastic in asphalt were optimum content.

3. Using plastic in road construction reduce noise pollution also because plastic has property to observe sound.

4. The waste plastic use in road construction improve the quality and performance of road.

5. By use of waste plastic reduce about $8 \%$ to $10 \%$ cost of asphalt in road construction

\section{ACKNOWLEDGEMENT}

This study would never be completed without help of God almighty. Whose blessing and exaltations flourished my thoughts and thrived my ambitions to eventually shape up the cherished fruit of my modest endeavors to this manuscript. We feel it an utmost pleasure to be able to express the hearties gratitude and deep sense of devotion to Engr. Mohsin Noor and Dr. Haroon Rashid for their attitude, constant help, valuable suggestion and criticism towards the completion of this project report. We also owe thanks to our family for their prayers and encouragement.

\section{REFERENCES}

[1] Chavan, A. J. 2013. Use of plastic waste in flexible pavements. International Journal of Application or Innovation in Engineering and Management, 2 (4), 540-552.

[2] Vasudevan, R., Sekar, A. R. C., Sundarakannan, B., and Velkennedy, R. 2012. A technique to dispose waste plastics in an ecofriendly wayApplication in construction of flexible pavements. Construction and Building Materials, 28 (1), 311-320.

[3] Swami, V., Jirge, A., Patil, K., Patil, S., Patil, S., and Salokhe, K. 2012. Use of waste plastic in construction of bituminous road. International Journal of Engineering Science and Technology, 4 (5), 2351-2355.

[4] Ghalayan, P., and Rana, E. S. 2017. Partial replacement of bitumen by using plastic waste in bitumen concrete. International Journal of Latest Research in Engineering and Computing, 5 (2), 7-12.

[5] Rokdey, S. N., Naktode, P. L., and Nikhar, M. R. 2015. Use of Plastic Waste in Road Construction. In International Journal of Computer Applications (0975-8887), International Conference on Quality Upgradation in Engineering, Science and Technology (ICQUEST2015).

[6] Al-Hadidy A.I., and Tan, Y. 2009. Effect of polyethylene on life of flexible pavements. Construction and Building Materials, 23, (3), 1456-1464.

[7] Huang, Y., Bird, R.N., and Heidrich, O. 2007. A review of the use of recycled solid waste materials in asphalt pavements. Resources, Conservation and Recycling, 52, 58-73.

[8] Sangita, Khan, T.A., Rashid, S., and Sharma, D. 2011. Effect of waste polymer modifier on the properties of bituminous concrete mixes. Construction and Building Materials, 25, 3841-3848.

[9] Jimenez, J.R., Ayuso, J., Agrela, F., López, M., and Galvín, A.P. 2011 Utilizations of unbound recycled aggregates from selected CDW in unpaved rural roads. Resources, Conservation and Recycling, 58, 88- 97. 